\title{
The supraclavicular artery island flap: a salvage option for head and neck reconstruction
}

\author{
Sanghoon Lee, Hye-Min Cho, Jin-kyu Kim and Woong Nam ${ }^{*}$
}

\begin{abstract}
Background: Some of head and neck cancer patients are in compromised general condition after ablation surgery and chemoradiation therapy, which makes secondary free tissue transfer quite challenging. Elderly cancer patients also have some risk for microvascular surgery with lengthened general anesthesia. In those cases, the pedicled flap vascularized by supraclavicular artery could be considered as an alternative to free flap. Despite several authors have demonstrated the clinical reliability of supraclavicular artery island flap (SCAIF), to date, SCAIF has not been widely used among reconstructive surgeon. In this article, we clarified vascular flow pattern and introduce simple surgical technique of SCAIF with a literature review.
\end{abstract}

Case presentation: Three patients who had underwent previous neck surgery and adjuvant therapy received maxillofacial reconstruction using SCAIF. It required only a few landmarks, flap harvesting was carried out, and the elapsed time gradually decreased to 15 min with experiences. There were no remarkable morbidities in both donor and recipient sites.

Conclusion: SCAIF exhibited minimal anatomic variations and short learning curve of surgical techniques, which might be valuable reconstruction modality for beginning surgeon. And it can be beneficial option for the patients with vessel-depleted neck, medically compromised status for lengthened general anesthesia and failed free tissue transfer.

Keywords: Mandibular reconstructive surgery, Cervicoplasty, Pedicled flap, Head and neck neoplasm,

Osteoradionecrosis

\section{Background}

The aim of head and neck reconstruction is not merely filling up defects, but include functional and esthetic restoration of three-dimensional structures. Advances in micro-vascular free flaps have enabled surgeons to achieve these goals on complex defects [1]. But micro-anastomosis can be troublesome task in case of repeated neck dissection or salvage procedure of free flap failure [2]. The different skin color and texture of a distant donor site also pose challenges for reconstructive surgeons [3]. In such cases, pedicled regional flaps should be employed as an alternative to free flaps. The regional flap nourished by supraclavicular artery (SCA) exhibits similar skin features and provides a thin and pliable skin paddle suitable for

\footnotetext{
* Correspondence: omsnam@yuhs.ac

Department of Oral and Maxillofacial Surgery, Yonsei University College of Dentistry, 50-1, Yonsei-ro, Seodaemoon-gu, Seoul 03722, Republic of Korea
}

mucosal and skin defects. In the past two decades, previous studies have demonstrated the reliability of supraclavicular artery island flap (SCAIF) for refractory defects from trauma, medication/radiation-induced osteonecrosis, and cancer ablation [4-6]. Nevertheless, utilization of this flap is currently rather limited among surgeons. In this case study, for ease of implementation by young reconstructive surgeons, we described a simplified surgical technique and clinical experience with brief literature review. The study was conducted according to the dictates of the Declaration of Helsinki and was approved by the Ethical Review Board of Yonsei University Dental Hospital Institutional Review Board (IRB No. 2-2017-0031). Informed consent was waived due to the retrospective nature of the study. All authors had access to the study data and reviewed and approved this study. 
Table 1 The characteristics of patients who underwent supraclavicular artery island flap reconstruction

\begin{tabular}{llllllllll}
\hline Case & Age/sex & $\begin{array}{l}\text { Underlying } \\
\text { disease }\end{array}$ & $\begin{array}{l}\text { Previous adjuvant } \\
\text { therapy }\end{array}$ & $\begin{array}{l}\text { Location } \\
\text { of defect }\end{array}$ & $\begin{array}{l}\text { Cause } \\
\text { of defect }\end{array}$ & $\begin{array}{l}\text { Flap } \\
\text { dimension }(\mathrm{cm})\end{array}$ & $\begin{array}{l}\text { Harvesting } \\
\text { time (min) }\end{array}$ & $\begin{array}{l}\text { Recipient site } \\
\text { morbidity }\end{array}$ & $\begin{array}{l}\text { Follow-up period } \\
\text { (months) }\end{array}$ \\
\hline 1 & 60/M & HTN DM & RT & $\begin{array}{l}\text { Upper neck } \\
\text { (skin) }\end{array}$ & ORN & $10 \times 20$ & 46 & None & 8 \\
2 & $82 / M$ & HTN HThR & RT & $\begin{array}{l}\text { Upper neck } \\
\text { (skin) }\end{array}$ & ORN & $9.0 \times 19$ & 33 & Wound dehiscence 6 \\
3 & 77/M & HTN & CCRT & Cheek (skin) & Recurred SCC & $9.5 \times 22$ & 19 & None & 6 \\
\hline
\end{tabular}

HTN hypertension, DM diabetes mellitus, HThR hypothyroidism, $R T$ radiotherapy, CCRT concurrent chemoradiotherapy, ORN osteoradionecrosis, SCC squamous cell carcinoma

\section{Case presentation}

Three patients underwent reconstruction of skin defect using SCAIF (Table 1). All patients had received wide excision of primary tumor followed by adjuvant therapy, two of whom had orocutaneous fistula derived from osteoradionecrosis (ORN), and the other patient was diagnosed with recurred squamous cell carcinoma in left buccal cheek as a metachronous second primary tumor. For proper healing process, debridement and excision of fibrotic skin was preceded in orocutaneous fistula patients. Flap elevation could be achieved by keeping supine position with slight neck extension in which ablation of tumor was carried out. The patient's arms are tucked at their side. SCAIF can be divided into two regions by clavicle: the proximal and distal (Fig. 1). The principal procedures are as follows:

First, mark the vascular flow using Doppler probe as far as the middle portion of upper arm [4]. Second, draw the flap outline with an elliptical shape within $5 \mathrm{~cm}$ of the most distal Doppler point for flap viability. Flap width should be less than $10 \mathrm{~cm}$ for primary closure of the donor site. Third, raise the flap from distal region including fascia. Once entering into the proximal region of SCAIF, surgeon should preserve the periosteum of clavicle and needs to begin careful dissection to secure vascular pedicle. Fourth, identify an origin of SCA. Within the area outlined by the superior border of clavicle, posterior border of sternocleidomastoid muscle (SCM) and external jugular vein (EJV), surgeon should pay attention about $2 \mathrm{~cm}$ above superior border of clavicle for the origin of SCA [7]. Fifth, skeletonize the pedicle. Pedicle including SCA and two venae comitantes should be bluntly or minimally skeletonized to prevent injury during rotation of flap (Fig. 2a, b). Sixth, adapt the flap into the defect. To establish a tunneling access, perform subplatysmal dissection in lower neck area and de-epithelize the proximal region of flap. Doppler probe test should be repeated until flap inset.

For flap harvesting, it took $46 \mathrm{~min}$ in the first case, but $15 \mathrm{~min}$ in the third one by senior surgeon. Any donor site morbidities were not shown in our case series. Patients 1 and 3 did not present any complication or recurrence of tumor after second operation (Fig. 3). However, patient 2 developed wound dehiscence at recipient

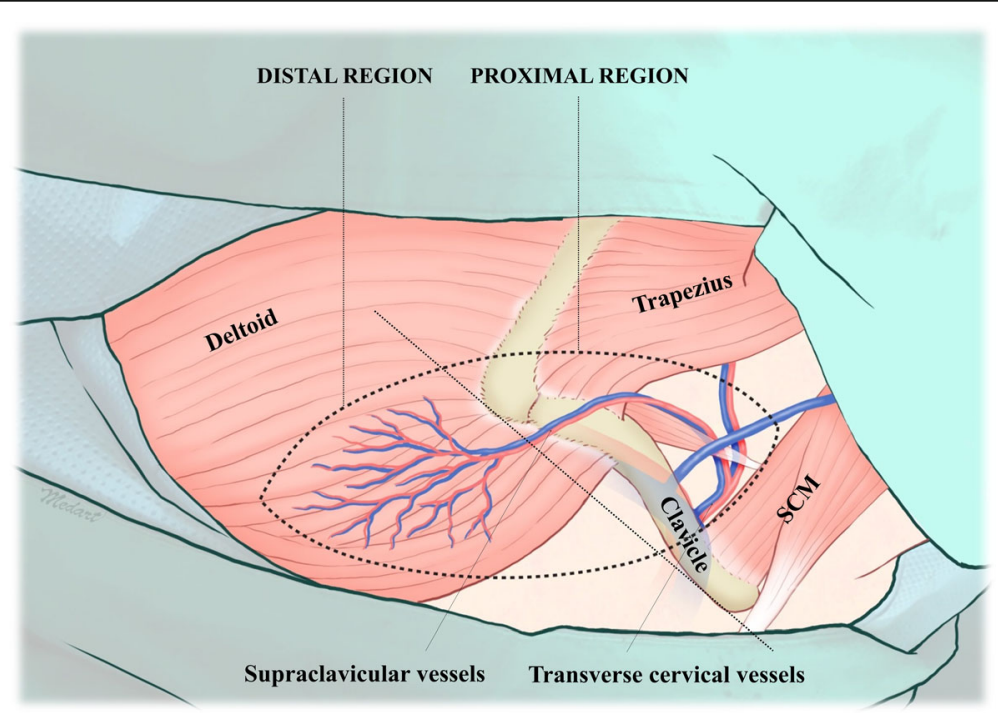

Fig. 1 Anatomy of the supraclavicular area (right side). Two regions were distinguished by dotted line depending on vascular flow pattern. Note the landmarks for the origin of supraclavicular vessels 

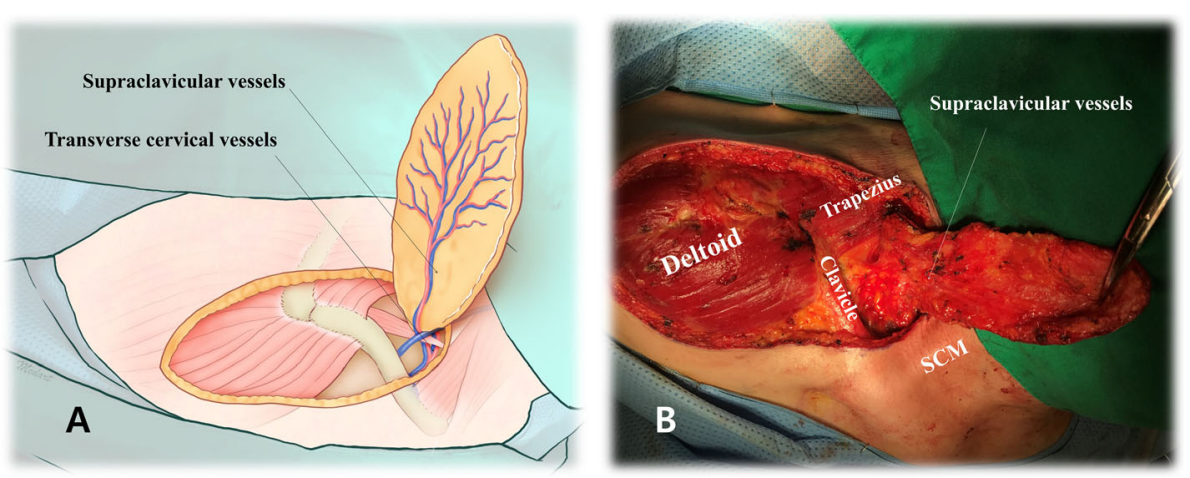

Fig. 2 Elevation of the supraclavicular artery flap (right side). a Vascular distribution after flap elevation. b Vascular pedicle was bluntly or minimally dissected to prevent injury

site, which was resolved with local wound care and vacuum assisted closure.

\section{Discussion}

In this case series, SCAIF demonstrated equivalent outcomes but rather required reduced operation time, costs, and less effort for perioperative care than free flap. It was done in straightforward process maintaining supine position, and total elapsed time was less than $2 \mathrm{~h}$. All patients were identified being in tolerable condition immediately after operation. Taking the concepts of simplicity, we realized that SCAIF can be a treatment of choice for the patients with vessel-depleted neck, medically compromised status for prolonged general anesthesia and failed free tissue transfer.

In accordance with the literature, the skin in supraclavicular area reproduced similar feature including color, texture, hair distribution, and thickness to those in the head and neck region $[2,3,5]$. Comparable to radial forearm free flap, SCAIF provides thin skin paddle suitable for reconstruction of upper and anterior neck area [8]. SCAIF exhibited favorable functional and esthetic results in our patients. There was no complaint from patients about appearance or movement of neck during follow-up period.
For rapid and precise flap elevation, the surgeon should consider the arterial flow pattern and origin of SCA. SCA begins at middle or lateral third of clavicle area with an axial pattern and gradually alters into a random pattern after passing through the clavicle [9]. We demarcated the regions according to this transition of arterial flow. In the distal region, subfascial dissection can be easily done without any morbidity. In proximal region, surgeon should protect vascular pedicle and focus on the origin of SCA. In case of repeated neck surgery in which SCM or EJV had been sacrificed, abovementioned landmark triangle is not available to detect the origin of SCA. The omohyoid muscle, which exists superficial to transverse cervical artery, should be identified prior to pedicle dissection $[10,11]$.

The common donor site morbidities are tolerable for SCAIF patients. Dehiscence or seroma formation was found in less than $15 \%$ of cases in perioperative period [12]. Hypertrophic scars might occur from huge tension along the donor site. If donor site defect is over $10 \mathrm{~cm}$ wide, split thickness skin graft rather than extensive undermining should be considered to facilitate wound healing $[5,10]$. Limitation of shoulder motion (abduction and external rotation) was found to be less than $20^{\circ}$, which is acceptable to daily living of patients [13].
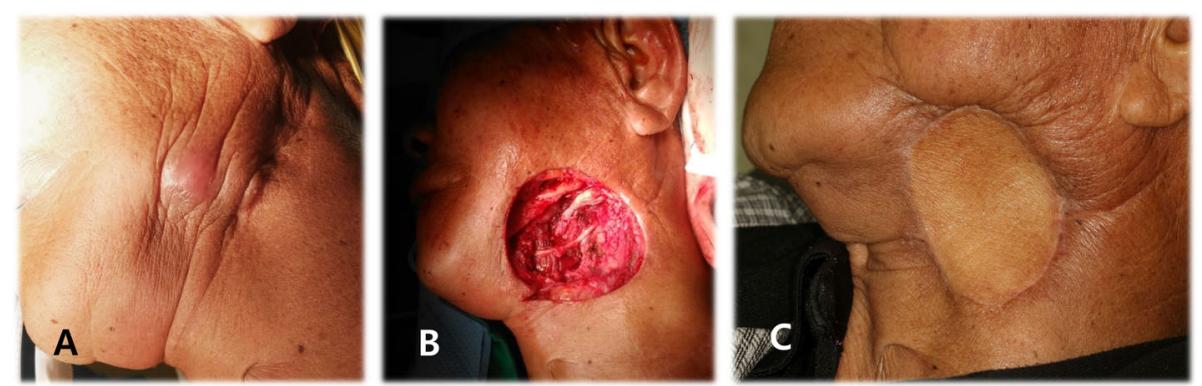

Fig. 3 Reconstruction of skin defect on mandible with the supraclavicular artery island flap in patient 3 (left side). a Skin lesion of $10 \times 9$ mm. b Skin defect of $20 \times 20 \mathrm{~mm}$. c Complete healing of recipient site at 4 months after surgery 


\section{Conclusions}

Though it was limited experience, we were able to implement SCAIF as a salvage modality in our case series. Further studies will be required to analyze the SCAIF with statistical analysis. SCAIF can provide a feasible alternative in refractory head and neck reconstruction, and short learning curve of surgical techniques is another advantage for young reconstructive surgeons.

\section{Abbreviations}

EJV: External jugular vein; ORN: Osteoradionecrosis; SCA: Supravlavicualar artery; SCAIF: Supravlavicualar artery island flap; SCM: Sternocleidomastoid muscle

\section{Authors' contributions}

WN contributed to the conception and design of the study, revision of the manuscript, and final approval. SL contributed to the acquisition of data, writing and revision of the manuscript, and final approval. HMC contributed to the acquisition of data, revision of the manuscript, and final approval. JK contributed to the revision of the manuscript and final approval.

\section{Ethics approval and consent to participate}

The study was conducted according to the dictates of the Declaration of Helsinki and was approved by the Ethical Review Board of Yonsei University Dental Hospital Institutional Review Board (IRB No. 2-2017-0031). Informed consent was waived due to the retrospective nature of the study. All authors had access to the study data and reviewed and approved this study.

\section{Consent for publication}

The method of this retrospective case report posed no more than "minimal risks" and that collection of data through noninvasive procedures (not including anesthesia or sedation) routinely employed in clinical practice and research including materials (data, documents, records, or specimens) that have been collected or will be collected solely for nonresearch purposes (such as medical treatment or diagnosis). Therefore, authors considered that consent for publication could be waived.

\section{Competing interests}

The authors declare that they have no competing interests.

\section{Publisher's Note}

Springer Nature remains neutral with regard to jurisdictional claims in published maps and institutional affiliations.

Received: 27 May 2018 Accepted: 20 August 2018

Published online: 04 October 2018

\section{References}

1. Cha YH, Nam W, Cha IH, Kim HJ (2017) Revisiting radial forearm free flap for successful venous drainage. Maxillofac Plast Reconstr Surg 39:14

2. Su T, Pirgousis P, Fernandes R (2013) Versatility of supraclavicular artery island flap in head and neck reconstruction of vessel-depleted and difficult necks. J Oral Maxillofac Surg 71:622-627

3. Kokot N, Mazhar K, Reder LS, Peng GL, Sinha UK (2013) The supraclavicular artery island flap in head and neck reconstruction: applications and limitations. JAMA Otolaryngol Head Neck Surg 139:1247-1255

4. Pallua N, Magnus Noah E (2000) The tunneled supraclavicular island flap: an optimized technique for head and neck reconstruction. Plast Reconstr Surg 105:842-851 discussion 52-4

5. Nthumba PM (2012) The supraclavicular artery flap: a versatile flap for neck and orofacial reconstruction. J Oral Maxillofac Surg 70:1997-2004

6. Welz C, Canis M, Schwenk-Zieger S, Spiegel JL, Weiss BG, Pilavakis Y (2017) Oral cancer reconstruction using the supraclavicular artery island flap: comparison to free radial forearm flap. J Oral Maxillofac Surg. https://doi. org/10.1016/j.joms.2017.02.017

7. Cordova A, Pirrello R, D'Arpa S, Jeschke J, Brenner E, Moschella F (2008) Vascular anatomy of the supraclavicular area revisited: feasibility of the free supraclavicular perforator flap. Plast Reconstr Surg 122:1399-1409
8. Lee Y, Hwang K (2002) Skin thickness of Korean adults. Surg Radiol Anat 24: 183-189

9. Ross RJ, Baillieu CE, Shayan R, Leung M, Ashton MW (2014) The anatomical basis for improving the reliability of the supraclavicular flap. J Plast Reconstr Aesthet Surg 67:198-204

10. Vinh VQ, Van Anh T, Ogawa R, Hyakusoku H (2009) Anatomical and clinical studies of the supraclavicular flap: analysis of 103 flaps used to reconstruct neck scar contractures. Plast Reconstr Surg 123:1471-1480

11. Tayfur V, Magden O, Edizer M, Menderes A (2010) Supraclavicular artery flap. J Craniofac Surg 21:1938-1940

12. Chiu ES, Liu PH, Friedlander PL (2009) Supraclavicular artery island flap for head and neck oncologic reconstruction: indications, complications, and outcomes. Plast Reconstr Surg 124:115-123

13. Herr MW, Bonanno A, Montalbano LA, Deschler DG, Emerick KS (2014) Shoulder function following reconstruction with the supraclavicular artery island flap. Laryngoscope 124:2478-2483

\section{Submit your manuscript to a SpringerOpen ${ }^{\circ}$ journal and benefit from:}

- Convenient online submission

- Rigorous peer review

- Open access: articles freely available online

- High visibility within the field

- Retaining the copyright to your article

Submit your next manuscript at $\boldsymbol{\nabla}$ springeropen.com 